\title{
Flecha FATAL
}

\author{
Elisabeth C.
}

\section{http://www.maissuperior. com/2014/04/27/fatal- 2014-o-teatro- universitario-regressa- lisboa/ (21-05-2014) \\ ${ }^{2}$ Feliz expressão poética da Professora Maria Helena \\ Serôdio que sintetiza o posicionamento do FATAL no texto de abertura publicado no Programa de Sala do FATAL 2000. \\ ${ }^{3}$ Permite a participação formativa e criativa de encenadores profissionais e apoia a organização do festival, o que é decisivo para os niveis de excelência a que esta mostra nos vem habituando. Refiram-se ainda as atuais parcerias \\ com outros agentes culturais da cidade, como a Caixa Geral de Depósitos \\ e a Câmara de Lisboa.}

Elisabeth C é professora (aposentada) do ensino secundário, integrou durante vários

anos a Direcção da Associação Portuguesa de Professores de Inglês

(APPI), onde é hoje formadora no seu Centro de Formação, e é Mestre em Estudos de Teatro pela Faculdade de Letras da Universidade de Lisboa. A sua dissertação

de Mestrado - Braz Burity: Tudo pela verdade - saiu recentemente (2014) publicada em livro, impresso pela Várzea da Rainha e com o apoio da Fundação da Casa de Bragança.

"0 Teatro [universitário], como espaço de criação e liberdade, de partilha das diversas experiências e linguagens, amplia a capacidade de reflectir, questionar e recriar vivências, a todos os que o constroem. No mundo da tão falada globalização, o Teatro é, pois, proximidade e identidade, ao focarse na construção da pessoa no seu todo e na compreensão do outro."

Como pontualmente acontece desde a sua criação, em 1999, este mês de Maio o FATAL - Festival Anual de Teatro Académico de Lisboa - voltou a animar a capital qual "flecha jovem no coração da cidade" ${ }^{2}$ lançada rumo ao futuro.

Porque se é no aqui e agora que se afirma como referência cultural dirigida a toda a comunidade, ultrapassando as fronteiras do teatro académico, "inscrevendo Lisboa no mapa das novas geografias das Artes do Espetáculo" (Regulamento 2014, art.o 2), é no futuro que se projeta pela sua componente formativa e pela sua capacidade de questionar e refletir sobre a arte, a condição humana e a vida.

Não será demais reafirmar, nestes tempos áridos e pardacentos de desinvestimento na cultura e de esvaziamento de objetivos e de sonhos, a importância crucial da atividade artística na Universidade e do Teatro Universitário em particular, na sua reconhecida condição de "atividade extracurricular estudantil de maior significado sociocultural e histórico no meio académico português"(/bidem, preâmbulo).

Ultrapassando o desafio colocado a encenadores, atores, técnicos e espetadores a pensar e repensar no teatro enquanto forma de expressão e criação, o teatro académico constitui uma privilegiada forma de reflexão e crescimento individual e coletivo, afirmando-se ainda - é oportuno lembrar - como importante veículo de integração dos jovens na vida universitária.

Na sua tradição de renovação do teatro no nosso país e de luta pela liberdade - estética, social e política - o teatro universitário tem constituído a rampa de lançamento de alguns dos nossos mais brilhantes profissionais das artes cénicas: atores e encenadores, como Luis Miguel Cintra e Jorge Silva Melo, bailarinos e produtores atualmente a trabalhar com a Mala Voadora, o Teatro Praga e a Companhia de Olga Roriz. Há ainda grupos que transitaram diretamente da universidade para a constituição de companhias, como foi o caso da ComunaTeatro de Pesquisa e dos Bonecreiros. $\mathrm{E}_{1}$ como aponta José Oliveira Barata, "o teatro universitário [...] nas suas lutas, êxitos e contradições, marcou várias gerações e interveio na vida cultural portuguesa"(Barata 2009: 341), constituindo a semente de onde tem brotado consideráve número de investigadores, professores, historiadores e dramaturgos.

Para os que seguem por outros caminhos, fica a formação humanistica, estética e cultural adquirida, benefícios individuais valiosos como o desenvolvimento das capacidades expressivas e criativas, bem como um mais profundo conhecimento sobre si próprio e o mundo à nossa volta. Fica uma experiência marcante de vida em comum e de uma prática de criação artística. Vivências que perduram e que podem mudar uma vida. E não será de menor importância o seu contributo na criação de um público conhecedor, que frequenta e aprecia o teatro, sabendo ver e discutir - como o confirma o elevado número de jovens espetadores que hoje encontramos nas salas de espetáculo.

Sobreviveria o nosso teatro universitário sem o FATAL? Naturalmente que sim, mas não se daria por ele. Muito se perderia, tanto em quantidade como em qualidade, dissipando-se a importante componente de motivação que constitui este espaço privilegiado de partilha e de saudável competição em que grupos de todo o pais se encontram e se confrontam, se conhecem, saem do seu isolamento, discutem conceções estéticas e técnicas, veem o trabalho dos outros e assim se enriquecem e se definem. 0 teatro universitário reduzir-se-ia a fortuitas e simples representações, sem ação cultural, a vagos projetos de "complementaridade cultural" (Ibidem. 336), como muitas outras atividades extracurriculares

Da responsabilidade da Reitoria da Universidade de Lisboa e com o apoio fundamental da Gulbenkian desde a primeira edição ${ }^{3}$, o festival, na sua missão de "promover e divulgar o Teatro Universitário português na sociedade" (Regulamento 2014, art. . 2) e "criar a apetência pelo Teatro junto do público jovem, bem como alargar a novos públicos a fruição das Artes do Espetáculo realizadas pelos estudantes universitários" (Idem., art. 5), constitui hoje um importante espaço de formação e promoção cultural na área do teatro e da performance, com uma adesão admirável de estudantes e de público.

A 15 a edição do FATAL, que decorreu entre 6 e 24 de Maio de 2014, no agradável espaço em que se insere o Teatro da Politécnica - no Museu Nacional da História Natural e da Ciência - e por outros locais da cidade, apresentou este ano a sua edição mais vasta e internacional, trazendo-nos 25 espetáculos de grupos portugueses e estrangeiros, tertúlias, workshops, performances, instalações e uma masterclass que preencheram dezoito dias intensos e estimulantes em que se viveu e respirou arte, liberdade e irreverência, como compete ao teatro universitário. 

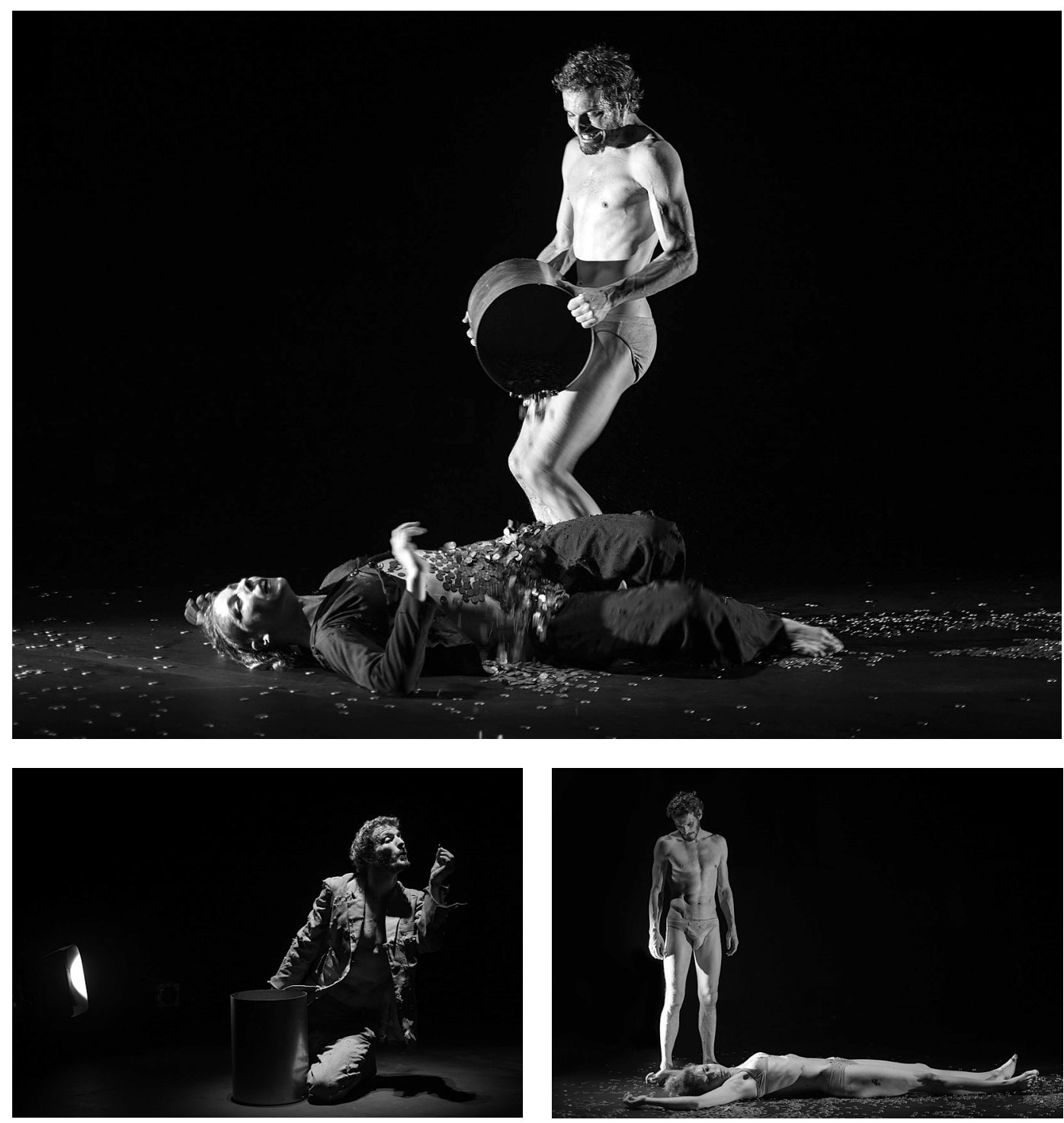

$\wedge<>$ criaçăo coletiva, dir. Matilde Javier Ciria, TEUC - Univ. Coimbra, 2014 (Cláudio Vidal e Rafaela Bidarra), fot. Zé Miguel Santos.

A apresentação pública, na Reitoria da Universidade de Lisboa, deu o tom de festa, começando pela habitual homenagem a "uma personalidade de relevo na História do Teatro Universitário" (Idem., art. ${ }^{4}$ 4), dedicada este ano a Emílio Rui Vilar pelo seu importante contributo para com as artes e a educação nacionais, nomeadamente para o desenvolvimento do Teatro Universitário Português. Para além da sua presença marcante na cultura nacional, o homenageado, no seu tempo de Coimbra "andou [...] pelos teatros" (Serôdio 2014: 2), tendo integrado o CITAC e sido criador do TUT, o grupo de teatro da Universidade Técnica de Lisboa, que dirigiu de 1981 a 2008. Como tal, foi com conhecimento de causa que apreciou as atividades teatrais como "das mais expressivas como veículo educativo cultural e artístico, constituindo um espaço de liberdade, criatividade e inovação, [...] que contribui para a renovação do teatro."

Em competição estiveram nove espetáculos, a que se juntaram oito integrando a categoria "Mais FATAL" (uma oportunidade para os grupos que, não tendo sido selecionados para a competição, tiveram ainda assim uma oportunidade para mostrarem as suas criações) e outros oito na categoria "FATAL Convida", que incluiu cinco espetáculos de grupos estrangeiros.
Marcaram presença alguns dos grupos de maior longevidade, como o GTL (Grupo Teatro de Letras da Universidade de Lisboa) o TEUC (Teatro dos Estudantes da Universidade de Coimbra), o TUT (Teatro Universitário de Lisboa - anterior Teatro da Universidade Técnica de Lisboa), o CITAC (Círculo de Iniciação Teatral da Academia de Coimbra), o TUP (Teatro Universitário do Porto),o GRETUA (Grupo Experimental de Teatro da Universidade de Aveiro), bem como outros de criação mais recente, como o Noster (Grupo de Teatro da Universidade Católica) e o Sin-Cera (Grupo de Teatro da Universidade do Algarve),

(re)afirmando-se como agentes culturais emblemáticos dos coletivos representados.

Tchekov, Strindberg, Raul Brandão e Shakespeare foram alguns dos autores que mereceram abordagens inovadoras nesta edição, embora grande parte dos grupos tenha apostado em criações coletivas a partir de pesquisas e da conjugação de esforços, dando largas à criatividade e exprimindo o seu "eu", individual e coletivo. Fizeram-no de formas diversas, prescindindo da palavra ou usandoa de forma complementar: pela dança, figurinos, iluminação, cenário, teatro visual, teatro não-verbal em detrimento da palavra, que em alguns casos surgiu de forma quase complementar, lateral. "Não se trata de 

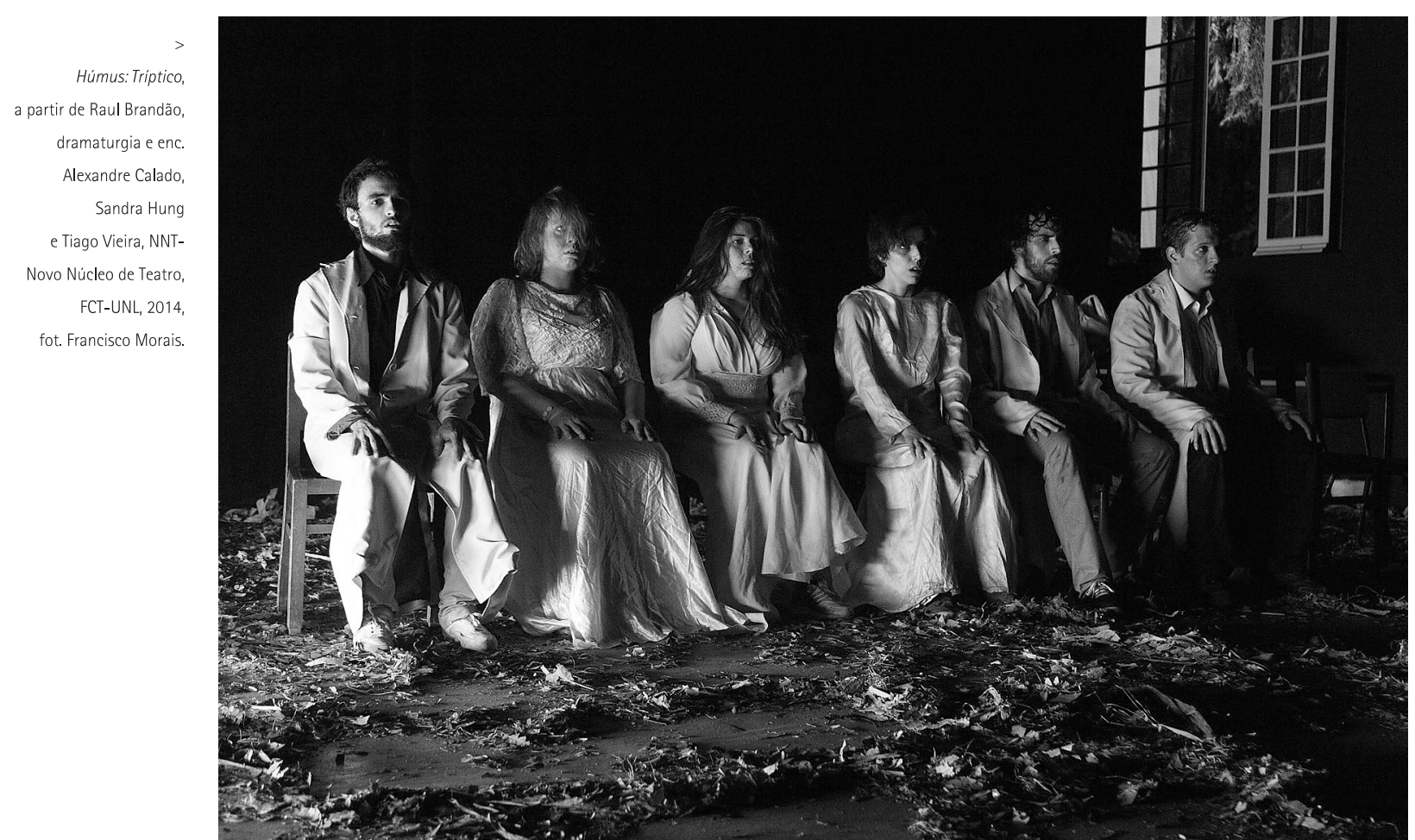

diminuir a importância do texto, mas de dar relevo ao corpo", diz Rui Teigão (Teigão 2014: 46). Como interpretar esta tendência? Reação ao excesso de linguagem que se verifica na sociedade contemporânea, nomeadamente nos discursos políticos e publicitários? Não estaremos a perder algo ao descrermos na palavra, elemento em que tradicionalmente se sustentava a criação da obra teatral? Questões que não são de agora, com que nos debatemos desde os vanguardistas e polémicos Artaud e Craig que há mais de um século puseram em causa o teatro textocêntrico..

Como já acontecera na edição anterior, os espetáculos não fugiram ao tema da crise económica e social. Mais ou menos pessimistas, muitos trabalhos revelavam sentimentos de desesperança, frustração, revolta, mas também de inconformismo e determinação, não faltando temáticas que envolviam o amor, o desejo e a luta pelo poder, a morte e a beleza, igualmente contemplados.

Como compete ao teatro universitário, a contenção de meios e a experimentação marcaram a generalidade dos trabalhos, produzindo resultados tão diversos quanto interessantes na procura de novas linguagens e novos formatos.

Passemos então em revista alguns dos espetáculos apresentados nesta edição do FATAL.

Corpo em crise, criação colectiva trazida pelo conceituado TEUC (Teatro dos Estudantes da Universidade de Coimbra) e dirigida por Matilde Javier Ciria, foi provavelmente o mais plástico dos espetáculos desta edição. Teatro sem palavras, absolutamente simbólico, em que a comunicação cénica se cumpriu pela música, pelos jogos de luz, pela cenografia, pelos figurinos, numa conjugação perfeita que envolve também a gestualidade dos atores. Criando o clima de revolta perante uma crise que não compreendemos e com que não nos devemos conformar, projetaram-se, com saber e arte, como introdução ao espetáculo, entrevistas às chamadas pessoas da vida real, a cujas perplexidades não podemos ficar indiferentes porque com elas nos identificamos. Com grande simplicidade de meios se faz muito: a partir de um pote com milhares de moedas de 2 cêntimos, simbolizando a ganância e a sobrevalorização do dinheiro que tanto desequilibram as nossas vidas, criaram-se imagens de rara beleza, que certamente perdurarão na memória dos espetadores. A insuperável interpretação, da responsabilidade de Cláudio Vidal e Rafaela Bidarra, foi física e plástica, atingindo um nível claramente profissional. Entrando-nos pelos sentidos, o seu frenesim artaudiano causou muitas vezes um grande incómodo no espectador: corpos em paroxismos de dor e desconforto, corpos em crise num mundo em crise.

Húmus, a obra-prima de Raul Brandão, em que, citando Virgílio Ferreira, "a morte se ergue como motivo contrastante para uma reflexão sobre a vida." serviu de base para um espetáculo tripartido do NNT (Novo Núcleo de Teatro da Faculdade Ciências e Tecnologia da Universidade Nova de Lisboa). Reunindo - de forma consistente - quadros que contavam com encenações próprias de Alexandre Calado, Sandra Hugo e Tiago Vieira enquadrados por imagens video de João Seiça, o espetáculo produziu um ambiente mágico a que não foi alheia a interpretação de grande entrega física e emotiva dos nove intérpretes. Numa primeira abordagem, cruzaram-se felizes recriações de excertos de textos clássicos - como Hamlet e Macbeth - com o tema da morte e da tragédia em pano de fundo, apresentando-se, por contraste, imagens vídeo a evocar a vida, árvores cujas raizes afinal se alimentam do húmus, a parte fértil da terra composta de detritos vegetais e animais, onde se entranham e confundem a morte e a vida, "todos apodrecendo juntos na mesma terra misturada e revolvida", de que falava Raul Brandão. A segunda abordagem, tendendo para alguma monotonia, centrou-se na leitura, nem sempre límpida, de trechos de Húmus. Três atrizes leram algumas páginas da escrita 


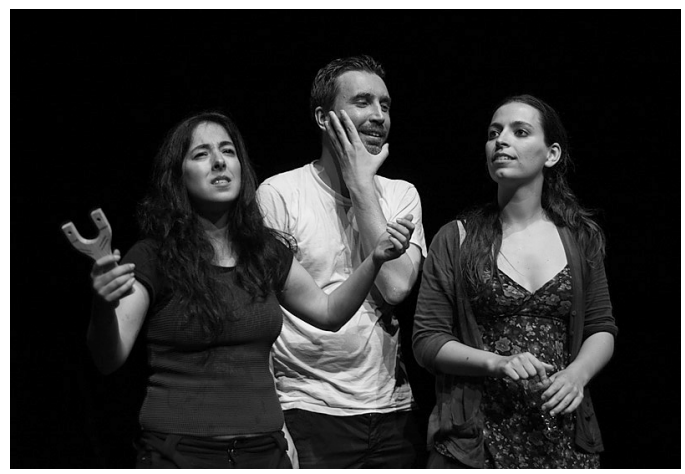

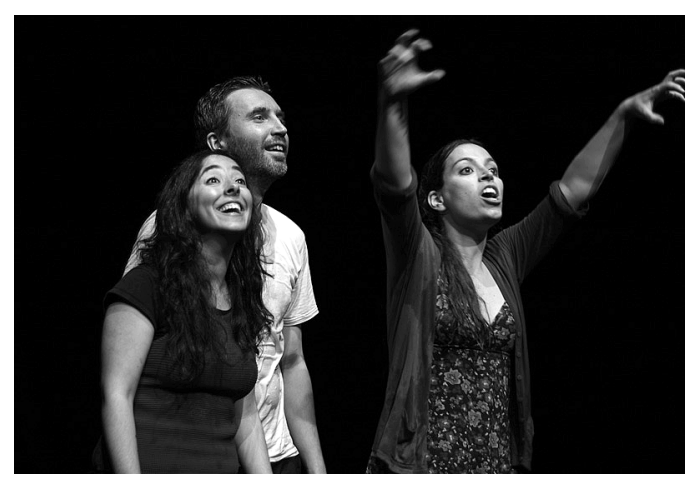

corrida de Raul Brandão, enquanto, de forma mecânica, circulavam pelo palco, com determinação, mas sem destino, os restantes intérpretes. Embora a conceção fosse convincente, o uso de microfones prejudicou a audição e nem sempre a leitura serviu a compreensão deste texto impar da nossa literatura, provocando alguma frustração no espetador. Na terceira abordagem, visual, criava-se um universo grotesco e onírico, surreal, em que se confunde a morte e a vida, em que o palco - revestido de detritos vegetais - é varrido por atores em transe progressivo. "0 sonho tem as suas raizes nos mortos", pois são eles que alimentam as profundas raizes da árvore dos vivos, seu "húmus essencial". Vive-se o inconformismo, a revolta da criatividade contra a imobilidade. Ouvimos o grito de revolta com que culmina a obra de Raul Brandão "É preciso matar segunda vez os mortos" e somos contagiados pela energia inesgotável deste empenhado grupo de intérpretes, que nos ofereceram ainda dois momentos perfeitos de canto tradicional. Três abordagens distintas a que o dedicado e versátil grupo de atores se entregou com dedicação, alma e nervos... até à exaustão física e emocional.

Ecstasy, o espetáculo do GNT (Grupo de Teatro da Nova) levou-nos a um palco ao ar livre - na Faculdade de Ciências Sociais e Humanas da Universidade Nova de Lisboa -, muito bem enquadrado no espaço e adaptado à função. Num pais de bom clima, mas sem grande tradição de espetáculos teatrais ao ar livre, a opção surpreendeu, mostrando-se, aliás, eficaz, inovadora e agradável - não tendo faltado mantas (que se revelaram desnecessárias por ter estado uma noite agradavelmente estival). Por uma vez, o texto foi a base sobre a qual se construiu o espetáculo concebido por Marina Albuquerque. Ecstasyé uma adaptação por Keith Wyatt do romance homónimo de Irvine Welsh, controverso autor de Trainspotting, um best seller que causou grande impacto quando da sua publicação e posterior adaptação ao cinema nos finais

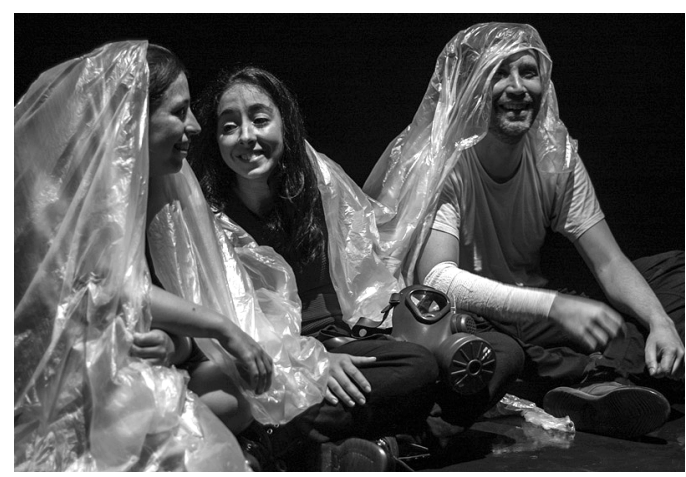

$\wedge<>$

No parque,

enc. Nicolas Brites,

GTIST - Inst. Sup. Técnico, 2014 ,

fot. Zé Miguel Santos.

dos anos 90. Na mesma linha (substituindo a heroína pelo ecstasy), a obra gira em torno do universo das drogas e do sexo, com diálogos primários, linguagem escabrosa e jovens estereotipados à procura de uma satisfação imediata, mas também da estabilidade emocional. Confrontam-se dois mundos, o das convenções sociais hipócritas e ocas, e o das emoções autênticas. As drogas, inicialmente celebradas, são condenadas no final, e a dependência rende-se ao que de melhor tem a vida: o amor verdadeiro e a estabilidade emocional. 0 ruido constante dos aviões que sobrevoam regularmente o espaço foi habilmente contornado pelo 'congelamento' da ação, logo retomada quando voltava o silêncio, acabando estes momentos de paragem por resultar muito agradáveis em contraste com o ritmo intenso em que se moviam os atores, numa sucessão de cenas e mudança de cenários e adereços. A utilização dos espaços laterais ao palco, nomeadamente do edifício contíguo, servida por uma iluminação eficaz, resultou muito bem. A interpretação, assegurada por um grupo de onze esforçados atores, nem sempre foi bem conseguida, com personagens pouco consistentes e demasiado presas ao texto, mas alguns belos momentos de dança constituiram pontos altos do espetáculo.

Já gastámos as palavras: noutro contexto que não o de uma relação que se esgotou, como no poema homónimo de Eugénio de Andrade, o TUT, após 65 anos a expressarse por palavras, optou pelo corpo do ator enquanto veículo de expressão e comunicação. "Estes gestos não podem ser explicados por palavras: se pudéssemos dizê-los, não haveria razão para dançá-los", esclarece Victor Hugo Pontes ${ }^{4}$, que dirigiu este espetáculo de teatro-dança tão imaculado quanto o branco chão em que se moviam harmoniosamente os treze intérpretes. Espetáculo de uma beleza plástica tocante, produto de um trabalho intenso e rigoroso, onde tudo acontece sem falhas e nada resulta do acaso, contemplativo, sem narrativa nem preocupação
${ }^{4}$ Cf. Programa do $15^{\circ}$ FATAL: ULisboa 2014 
de Irvine Welsh

(adapt. Keith Wyatt) enc. Marina Albuquerque GTN - FCSH Univ. Nova

de Lisboa, 2014,

fot Joana Azevedo.

Já gastámos as palavras,

dir. Victor Hugo Pontes, TUP - Porto, 2014, fot Tânia Araújo.

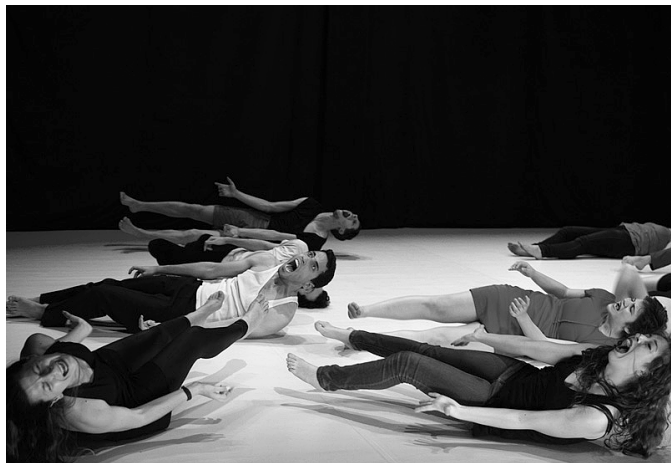

Dostoyevsky trip de Vladimir Sorokin. enc. Júlio Martin d Fonseca, TUT - Univ.

Lisboa, 2014

fot. Mário Corromeu com temas sociais ou emocionais, mas limpo e encantador conjugando-se com sábios jogos de luz e a surpreendente música original de Rui Lima e Sérgio Martins.

No parque foi o espetáculo honesto e despretensioso coletivamente criado pelo GTIST (Grupo de teatro do Instituto Superior Técnico) com encenação de Nicolas Brites. Estamos perante as inquietações da juventude, convidada a sair da sua bolha de conforto (habilmente cenografada) para se debater com ideais utópicos em confronto com uma realidade degradante. Porque é preciso sonhar e refletir, mesmo que à bolha se regresse, como é inevitável. A água é o principal elemento cenográfico numa sucessão de cenas bem conseguidas - para além de materiais simples como plásticos e panos, engenhosamente manuseados (ou não estivéssemos na presença de futuros engenheiros) de forma a criar efeitos surpreendentes - para o que concorre o adequado desenho de luz. A linguagem, a raiar o absurdo, é pontuada por um humor muito saboroso, não deixando de convidar à reflexão. A interpretação, de uma simplicidade cativante, de mãos dadas com a espontaneidade, facilitou a identificação e a empatia do espetador. 0 espetáculo universitário tout court, que cativa pela simplicidade desarmante, pela criatividade, pela irreverência, pela jovialidade

\section{Conclusão}

Atestando o impacto do evento lisboeta, muitas centenas de espetadores interessados e calorosos marcaram presença, muitos deles 'contaminados' em edições anteriores, vivendo alegremente o contagiante entusiasmo dos grupos e o saboroso clima de descontração, criatividade convívio e sã competitividade. De salientar a elevada participação do público nas discussões/tertúlias pósespetáculo, com a presença do elenco, e que constituíram momentos de reflexão e debate cultural.
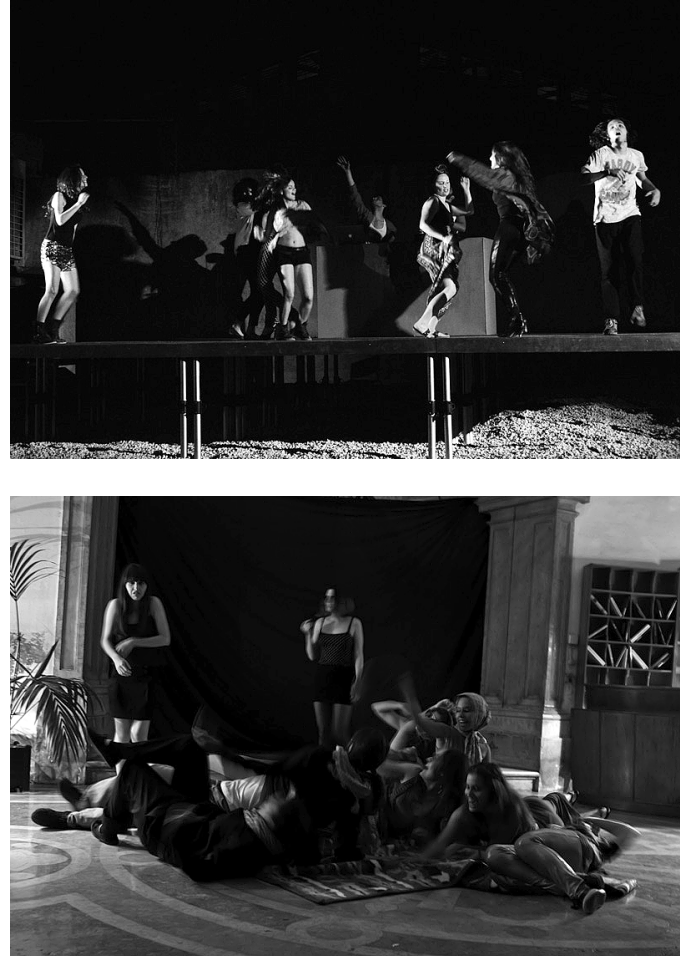

Evidenciando um trabalho esforçado e empenhado, os grupos foram de uma entrega total, emprestando toda a sua vitalidade ao momento que foi (/será), porventura um dos mais marcantes da sua vida. Mostrou-se vivo e de boa saúde, o FATAL. Que assim continue, neste ambiente mágico de festa, entrega, união, descoberta, experimentação, de dar tudo por tudo. Ambiente que nos renova e que reacende a esperança num futuro em que o lugar do teatro na vida cultural do pais se torne cada mais consistente.

\section{Referências bibliográficas e sitiográficas}

BARATA, José Oliveira (2009) Máscaras da utopia, Lisboa, Fundação Calouste Gulbenkian BRANDÃO, Raúl (1917) Húmus, Porto, Renascença Portuguesa.

Programa $15^{\circ}$ FATAL (2014), disponivel no sitio: http://www.fatal.ul.pt/programa.htm Regulamento FATAL (2014), disponivel no sitio:

http://www.fatal.ul.pt/festival_regulamento.htm

SERÔDIO, Maria Helena (2014), "Entre-linhas: o lugar de Emilio Rui Vilar na arquitectura

da vida... e do teatro", in programa do $15^{\circ}$ Festival Anual de Teatro Académico de Lisboa.

TEIGÃO, Rui (2014), Entrevista à Time Out de 30 de Abril, p. 46. $<$ www.maissuperior.com> 